\title{
Review \\ Requirement of macrophages and eosinophils and their cytokines/chemokines for mammary gland development
}

\author{
Valérie Gouon-Evans ${ }^{1}$, Elaine Y Lin ${ }^{1}$ and Jeffrey W Pollard ${ }^{2}$
}

\author{
1'Department of Developmental and Molecular Biology, Albert Einstein College of Medicine, Bronx, New York, USA \\ ${ }^{2}$ Department of Obstetrics \& Gynecology and Women's Health and Center for the Study of Reproductive Biology and Women's Health, Albert Einstein \\ College of Medicine, Bronx, New York, USA
}

Correspondence: Jeffrey W Pollard, Albert Einstein College of Medicine, DMB Chanin 602, 1300 Morris Park Ave., Bronx 10461, NY, USA.

Tel: +1 718430 2090; fax: +1 718430 8972; e-mail: Pollard@aecom.yu.edu

Received: 26 March 2002

Revisions requested: 4 May 2002

Revisions received: 7 June 2002

Accepted: 10 June 2002

Published: 25 June 2002
Breast Cancer Res 2002, 4:155-164

(C) 2002 BioMed Central Ltd

(Print ISSN 1465-5411; Online ISSN 1465-542X)

\begin{abstract}
Epithelial/mesenchymal cell interactions are necessary for proper ductal morphogenesis throughout all stages of mammary gland development. Besides the well-established stromal components, such as adipocytes and fibroblasts, the mammary stroma is also infiltrated with migrating blood cells, mostly macrophages and eosinophils. The focus of this review is on the role of macrophages and their growth factor colony-stimulating factor 1 (CSF-1) in promoting branching morphogenesis during postnatal mammary gland development through to lactation. The more restricted role of eosinophils and their chemoattractant eotaxin during pubertal ductal morphogenesis is also discussed. A possible interaction between macrophages and eosinophils in ductal morphogenesis is considered, along with the roles of other chemokines. This role of macrophages in normal development also appears to be subverted by tumors of the mammary gland to promote the escape of the tumor cells from the local environment and enhance their rate of metastasis. These data emphasize the dual role of macrophages in the promotion of epithelial growth in normal and cancer states.
\end{abstract}

Keywords: breast cancer, CSF-1, eosinophils, eotaxin, macrophages, mammary glands

\section{Introduction}

It is well established that epithelial/mesenchymal interactions are important for postnatal development of the mammary ductal tree and its differentiation during pregnancy into a milk-producing structure [1]. The mesenchyme contains a heterogeneous group of cells [2] and several of these, such as fat cells and fibroblasts, are capable of producing factors that can promote the growth of epithelial cells [3-6]. This review focuses on the role of two types of migrant hematopoietic cells, macrophages and eosinophils, that have been recently found to accumulate extensively around terminal end buds (TEBs) during the pubertal burst of ductal growth [7]. Their chemoattractant factors and their roles in mammary cancer are also discussed.

\section{Leukocyte homing to the mammary gland}

The stroma of the mammary gland is composed of various cells including adipocytes, fibroblasts, endothelial cells, nerve cells and migratory leukocytes [8]. Immunohistochemical analysis using anti-F4/80 antibody revealed two cell types, macrophages and eosinophils, whose recruitment to the postnatal mammary gland closely parallels the formation and outgrowth of terminal end buds (TEBs)

CSF-1 = colony-stimulating factor 1 or macrophage-colony-stimulating factor; CSF-1R = colony-stimulating-factor- 1 receptor; $I L=$ interleukin; $M E C=$ mammary enriched chemokine; MMTV = mouse mammary tumor virus; RANK(-L) = receptor activator of nuclear factor $\kappa B$ (ligand); TEB $=$ terminal end bud; TNF = tumor necrosis factor. 
Figure 1

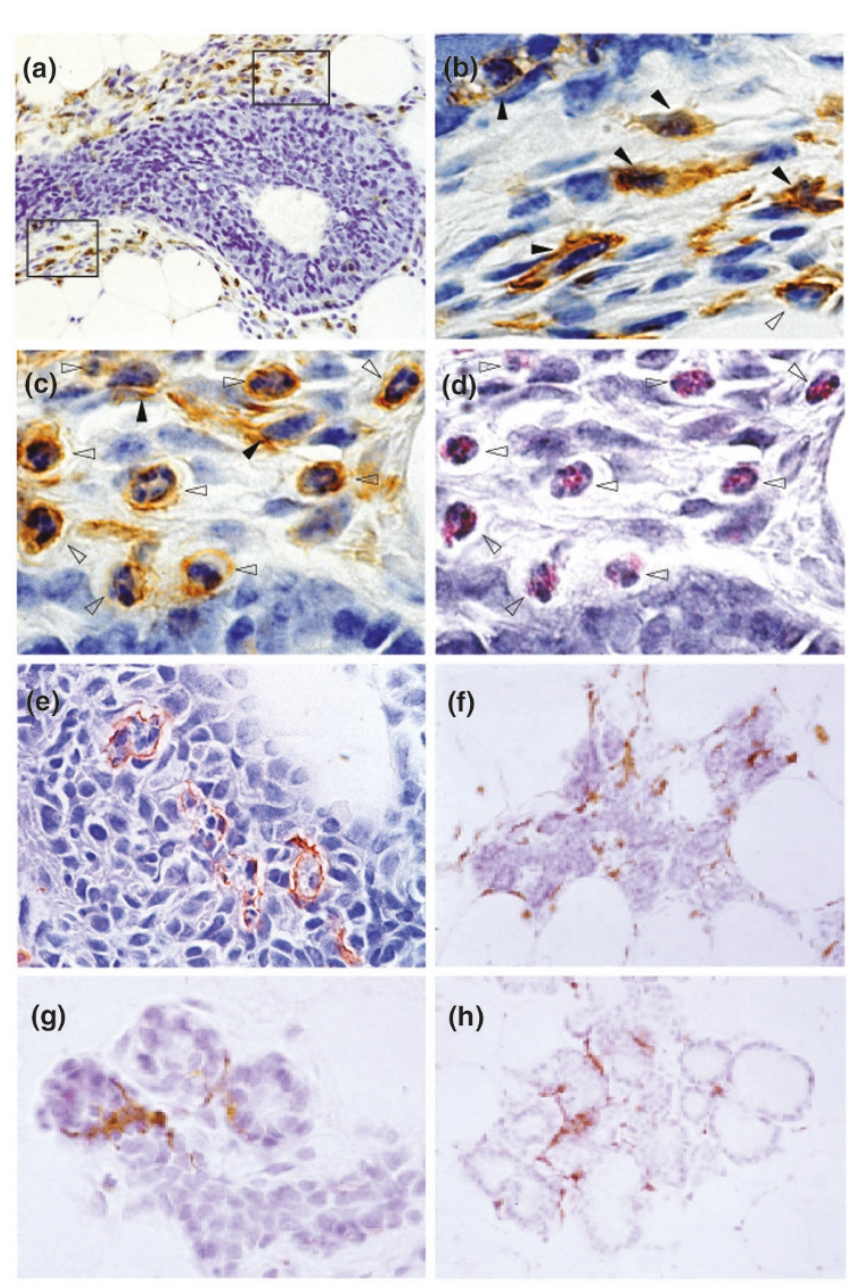

(Fig. 1a-e) [7]. Although F4/80 was originally described as a murine macrophage-restricted cell-surface glycoprotein [9], it is also expressed in eosinophils (see Fig. 1c), which can be independently identified by their specific eosinophilic cytoplasmic granules (see Fig. 1d). The distribution of macrophages and eosinophils around TEBs overlaps, although macrophages are mostly recruited to the neck while eosinophils are more numerous around the head of the TEB. When other leukocyte-lineage markers such as B220, CD3 and Gr-1 are used, neither B cells, $T$ cells nor neutrophils are detected in the vicinity of epithelial structures in the developing mammary gland during puberty, even though they are present in the lymph node localized in the middle of the fourth abdominal mammary gland. Macrophages and eosinophils are also found during pregnancy and lactation around the lobuloalveoli, although macrophages are more numerous (Fig. 1f-h).

An association between the developing lobulo-alveolar structures during pregnancy and mast cells has been reported in mice, while the density of these cells decreased during lactation [10]. In a healthy state in a variety of species, macrophages constitute a major cellular component of the milk [11-14]. Lymphocytes, although largely absent from the pubertal mammary gland, are an important cellular component of the gland during lactation, supplying maternal antibodies and $\mathrm{T}$ cells to the milk [14-19]. Involution is characterized by abundant leukocyte homing into the mammary gland, since all leukocytes are represented in the involution secretion in various species [20-22]. In fact, in the milk of commercial species, the somatic cell count that includes leukocytes and epithelial cells is used as an indicator of udder health status. A somatic cell count above the regulatory standard is generally considered to be an indication of mastitis. The role of leukocytes during pathologic states of the mammary gland such as mastitis, when neutrophils together with macrophages are abundant, will not be addressed here, but is reviewed extensively elsewhere $[23,24]$. This review is focused on macrophage and eosinophil biology in the mammary gland.

\section{Leukocytes are required for postnatal mammary gland development}

The hypothesis that leukocytes are important for the development of the mammary gland was tested by depleting mice of circulating leukocytes using semilethal gammairradiation to remove hematopoietic progenitors [7]. A single exposure to gamma-irradiation led to a $97 \%$ decrease in leukocyte number in the blood 5 days after irradiation. At this dose, proliferation of mammary gland epithelial cells was not affected, as assessed by incorporation of $\mathrm{BrdU}$ in irradiated versus nonirradiated mice. However, removal of the hematopoietic system by gamma-irradiation resulted in a dramatic curtailment of

\begin{abstract}
arrowheads) and their segmented nucleus, sometimes in a ring shape with a round cytoplasmic shape (b,c,d, empty arrowheads). In contrast, $\mathrm{F} 4 / 80^{+}$macrophages have a large, oval nucleus with a spread cytoplasm (b,c, filled arrowheads) containing no eosin-pink cytoplasmic granules. (e) The presence of macrophages inside the TEB, where they engulf apoptotic epithelial cells. (f-h) F4/80 immunostaining of mammary sections at day 16 of pregnancy $(\mathrm{f}, \mathrm{g})$ and day 2 postpartum (h). Note the abundance of macrophages tightly associated with the lobulo-alveoli during pregnancy and lactation. Original magnification: $a, f, h, 400 x ; b, c, d, e, g$ 1000x. Panels a-e modified from [7].

development and differentiation. (a-e) Longitudinal paraffin section of a terminal end bud (TEB) was stained twice, first with immunostaining with anti-F4/80 antibody and counterstaining with magnification pictures of (a): (b) bottom frame; (c,d) top frame. The antibody for macrophages ( $b$, filled arrowheads), mainly seen in the neck of the TEB (bottom frame, a) and for eosinophils (c,d, empty $\mathrm{F} 4 / 80^{+}$eosinophils were distinguished from $\mathrm{F} 4 / 80^{+}$macrophages by
\end{abstract}


ductal development. TEBs were completely absent at the tips of the ducts and the mammary gland retained a neonatal appearance (Fig. 2a,b). Transplantation of syngenic bone marrow into the irradiated mice reconstituted the leukocyte population in the blood and the macrophage and eosinophil density around the TEBs, and completely rescued ductal outgrowth (Fig. 2c,d). No other leukocytes were found around the ducts, as assessed by specific immunohistochemistry with antibodies against lymphocytes and neutrophils. Occasionally, cells with the morphology of mast cells could also be detected around the ducts in the nipple area, but these were not further investigated. These data strongly support the hypothesis that macrophages and eosinophils play an essential role in mammary ductal morphogenesis.

CSF-1, or macrophage-colony-stimulating factor 1 , is a dimeric polypeptide growth factor that regulates the survival and proliferation of the mononuclear phagocytic lineage (monocytes, macrophages, osteoclasts and microglia) [25-27], as well as affecting macrophage behavior, morphology and motility $[28,29]$. The single class of receptor for CSF-1 (CSF-1R) is encoded by the c-fms proto-oncogene and is a member of the class III family of transmembrane-receptor tyrosine kinases [30]. Binding of the dimeric CSF-1 initiates dimerization of the receptor, resulting in auto-transphosphorylation and the subsequent phosphorylation of downstream target proteins on tyrosine residues [31-33]. The critical roles of CSF-1 in macrophage biology were confirmed by analysis of the osteopetrotic mouse that has a null mutation in the CSF-1 gene (Csf1op/Csf1op mouse) [34-36], and in more recent work in the CSF-1R-null mutant mouse [37]. Both the ligand- and receptor-deficient mice are severely depleted in many populations of macrophages and circulating monocytes $[36,37]$. The similarities between the phenotypes of the receptor- and ligand-null mutant mice indicate that the CSF-1R is the only receptor for CSF-1.

The macrophage density in mammary glands during postnatal outgrowth, pregnancy and lactation was significantly lower in Csf10p/Csf1op mice (Fig. 3b,d,f,h) than in control mice (Fig. $3 \mathrm{a}, \mathrm{c}, \mathrm{e}, \mathrm{g}$ ) [7]. $\mathrm{F} 4 / 80^{+}$macrophages are tightly associated with alveoli in control mice at all stages, while the very few macrophages seen in Csf1op/Csf1op mice (filled arrowheads, see Fig. $3 d$ ) are not adjacent to the alveoli, and most of the $\mathrm{F} 4 / 80^{+}$cells are eosinophils (empty arrowheads, see Fig. 3d). A failure of ductal outgrowth and the precocious development of the lobuloalveoli units during pregnancy, previously observed in the mammary glands of Csf1op/Csf1op mice [38], are confirmed by histology showing the well-differentiated alveoli formed at day 14 of pregnancy (see Fig. 3b,d) in comparison with those in control mice (see Fig. $3 a, c)$. At day 18 of pregnancy in mutant mice, these units have already developed (see Fig. 3f) to a stage similar to those seen in lac-

\section{Figure 2}
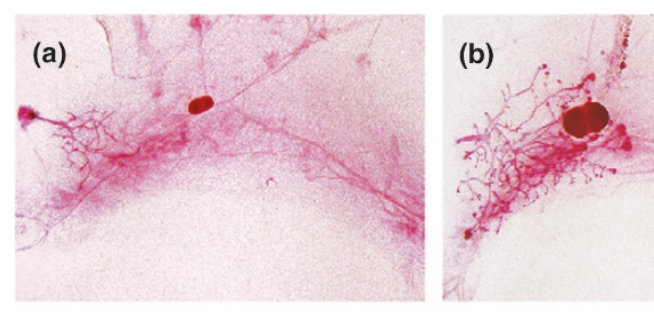

(c)

(d)

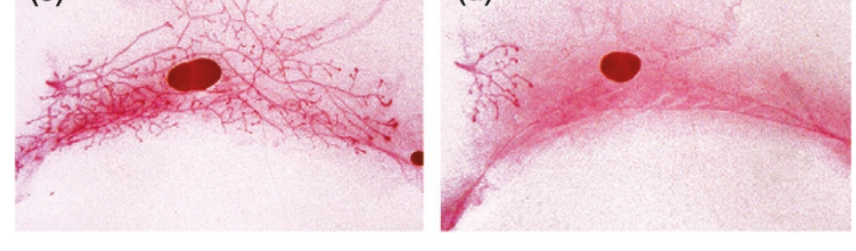

Leukocytes are necessary for mammary ductal outgrowth.

$(\mathbf{a}, \mathrm{b})+/ C s 1^{\circ o}$ mice were irradiated (700 rads, gamma-irradiation) at 19 days of age. A representative mammary gland whole-mount preparation obtained 10 days after irradiation is illustrated (a), in comparison with the nonirradiated control (b). (c,d) $+/$ Csf1op mice underwent gamma-irradiation (700 rads) at 19 days of age and 2 hours later were (c) or were not (d) given a transplant of a bone marrow cell suspension from $+/$ Csf1 op mice. Representative whole-mount preparations obtained 28 days after irradiation/transplantation (c) and from an irradiated control mouse that did not undergo bone marrow transplantation (d) are shown. Note the restoration of ductal outgrowth after bone marrow transplantation. All the photomicrographs shown are of whole mounts from the entire fourth abdominal mammary gland and were taken at the same magnification. Modified from [7].

tating gland from control mice (see Fig. $3 \mathrm{~g}$ ). However, the secretory units have almost completely disappeared in mutant mice at day 4 postpartum and started to involute because of the lack of suckling by the pups. Similar defects in branching morphogenesis during pregnancy were found in the CSF-1R-deficient mice, supporting the crucial role of CSF-1 in mammary gland development [37]. Besides this aberrant epithelial differentiation, a defect in proper ductal outgrowth during puberty was also observed in CSF-1-null mutant mice, as assessed from the total numbers of branches including primary, secondary and tertiary ducts, TEB numbers, and ductal length [7]. Daily treatment of CSF-1-deficient mice with CSF-1 from birth corrected the pubertal ductal outgrowth defect in terms of TEB formation and total branch numbers and brought the mammary macrophage population to normal. This points out the close correlation between the presence of macrophages and proper ductal morphogenesis [7].

Because Csf1op/Csf1op mice have a number of phenotypes that could have a bearing on mammary gland development, including a perturbed sex steroid hormone feedback in the hypothalamus leading to aberrant estrous cycling [39], a transgenic approach was used to determine whether CSF-1 acts directly in the mammary gland or through a systemic effect. Transgenic mice that specifically 
Figure 3

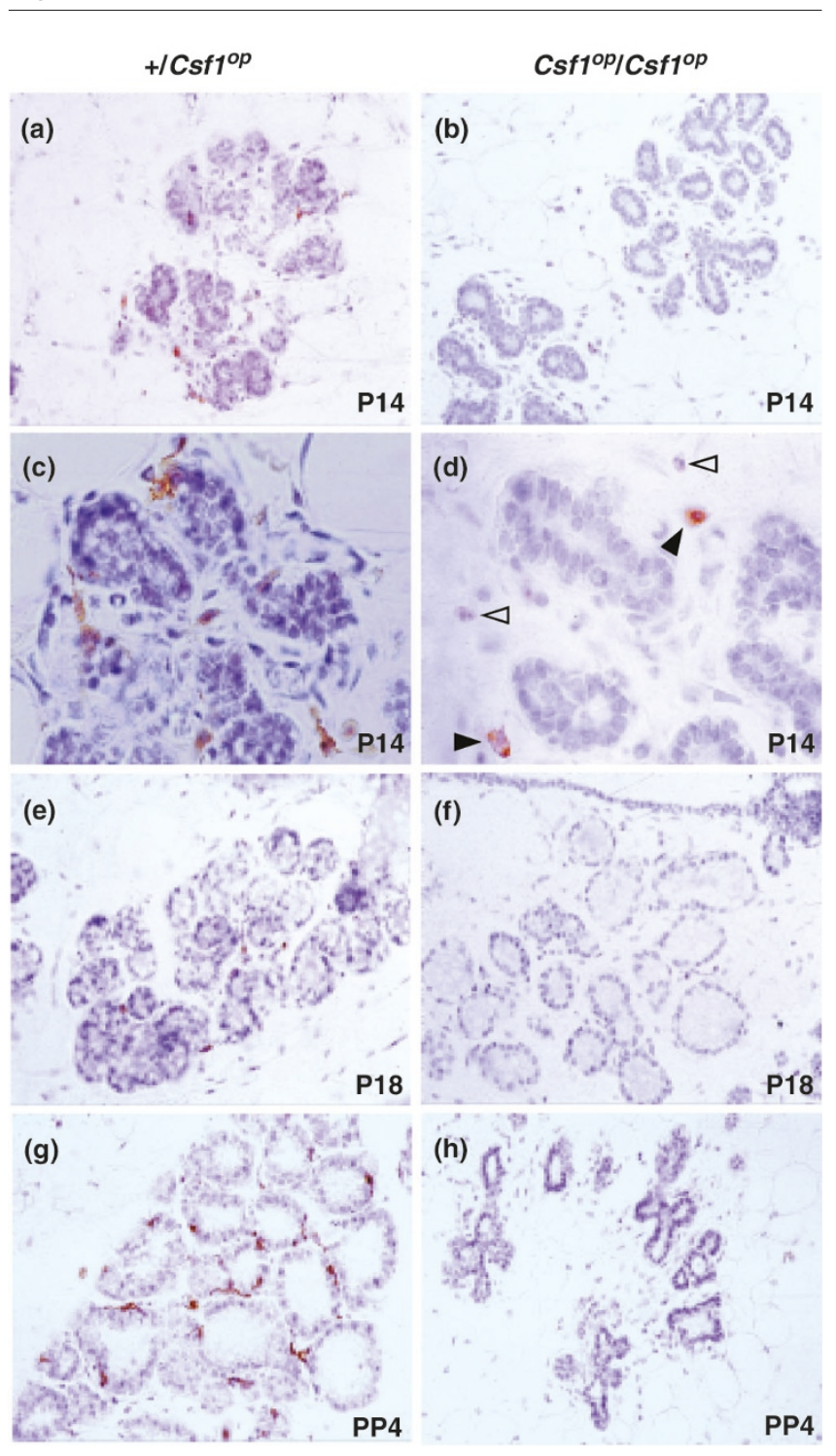

Macrophage distribution in mammary glands of $+/ \mathrm{Csf} 1^{\circ \mathrm{p}}$ control and Csf1 ${ }^{\circ / C} /$ sf1 $1^{\circ}$ mice during pregnancy and lactation. F4/80 immunohistochemistry of mammary section of day $14(\mathrm{P} 14 ; \mathbf{a}-\mathrm{d})$ and day $18(\mathrm{P} 18 ; \mathbf{e}, \mathrm{f})$ of pregnancy and day 4 postpartum of lactation (PP4; g,h) from control (a,c,e,g) and Csf1op/Csf1op (b,d,f,h) mice. Note the abundance of $\mathrm{F} 4 / 80^{+}$macrophages tightly associated with alveoli in control mice at all stages shown, while macrophages are almost absent in Csf1op/Csf1 op mice at all stages of mammary development. The few macrophages (filled arrowheads, d) seen in Csf10p/Csf1op mice are not adjacent to the alveoli, and most of the F4/80 cells seen are eosinophils (empty arrowheads, d). Original magnification: a,b,e,f,g,h: $\times 400 ; c, d: \times 1000$.

restored CSF-1 to the mammary epithelium by expressing CSF-1 under the control of mouse mammary tumor virus (MMTV) promoter were crossed with Csf10p/Csf1op mice [40]. CSF-1 was undetectable in the serum and there was no correction of phenotypic features of the weight, toothlessness, or the extended estrous cycle. Furthermore, there was no correction of macrophage density in organs other than the mammary and salivary glands, where the MMTV promoter is also active. However, the expression of CSF-1 in the mammary epithelium corrected the ductal outgrowth significantly as well as restoring macrophage recruitment in Csf10p/Csf1op mice. This indicated that the defects observed in the mammary glands of CSF-1-null mutant mice are not due to secondary effects induced by a systemic CSF-1 deficiency [40].

Mammary epithelial cells seem to produce CSF-1 during mammary development. The ducts in mice expressing a $\beta$-galactosidase reporter gene under the control of the CSF-1 promoter were strongly positive for $\beta$-galactosidase during development and pregnancy, indicating epithelial synthesis of CSF-1 [41]. However, mammary transplantation experiments indicated that this CSF-1 synthesis was not necessary for macrophage recruitment [40]. Immunohistochemical and in situ hybridization studies in human breast tissue showed that normal, nonlactating epithelial cells synthesize significant amounts of CSF-1, which is upregulated in lactating epithelium in vivo and in vitro $[13,42,43]$. Moreover, a high concentration of biologically active CSF-1 is present in human milk, with the maximum being observed on day 2 postpartum, before declining rapidly one month after delivery [13]. The CSF-1 receptor (CSF-1R) is exclusively expressed in macrophages in the mammary gland tissue of virgin mice [7] and has not been reported in normal, human, resting, nonlactating epithelial breast tissue $[42,44]$. In contrast, during pregnancy and lactation, CSF-1R is highly expressed in both the mammary epithelium and macrophages in humans, but only in macrophages in mice $[43,44]$ ( $L$ Zhu and JW Pollard, unpublished data). Thus, the pattern of CSF-1 expression in humans and mice is quite similar, although there are differences in the identity of CSF-1R bearing cells. Consequently, the regulation of the local CSF$1 /$ CSF-1R system appears to be crucial for ductal outgrowth and epithelial differentiation functions through paracrine mechanisms, although in humans, there might also be an autocrine component.

Overall these data indicate functions for macrophages in ductal outgrowth and differentiation, possibly acting through their well-documented roles in supplying trophic factors for epithelial cell growth, angiogenesis or matrix remodeling but also through their phagocytic activity [45-47]. In fact, a unique location for macrophages inside the body of well-formed TEBs was systematically found in control mice (see Fig. 1e), and these cells were absent in Csf10p/Csf1op mice [7]. In this particular case, macrophages engulfed apoptotic epithelial cells and were restricted to the proximal area of the lumen within the TEB (see Fig. 1e), suggesting their participation in the lumen 
formation which requires epithelial apoptosis $[48,49]$. Consequently, the absence of this particular macrophage function might in part explain the compromised ductal outgrowth in Csf1op/Csf1op mice.

\section{CSF-1 and macrophages in breast cancer}

Substantial evidence indicates that over-expression of CSF-1 and CSF-1R in human breast cancer correlates with poor prognosis $[50,51]$. Because macrophages can serve as both positive and negative mediators of the immune system, the importance of macrophages in tumor growth remains controversial [52-54]. Nevertheless, there is a growing literature showing that tumor-derived molecules redirect macrophage activities to promote tumor development, establishing a positive correlation between macrophage infiltration into the breast tumor stroma and poor prognosis $[51,55-58]$. Therefore, we have proposed a model in which macrophages may supply common trophic substances to tumors to facilitate their growth, invasiveness and metastatic ability in a similar manner as they do to the developing TEB during the ductal invasion at puberty (Fig. 4). Such substances could be angiogenic factors (vascular endothelial growth factor, angiopoietin-1), proteases (matrix metalloproteinase-9, urokinase plasminogen activator), growth factors (epidermal growth factor) or cytokines (tumor necrosis factor alpha). In both these processes, CSF-1 as well as other chemokines produced by the normal or tumorigenic epithelium are necessary for macrophage homing into the gland (see Fig. 4).

To test this hypothesis and to investigate whether the clinical correlations had a causal basis, we crossed CSF-1null mutant mice with a strain susceptible to mammary tumors because of overexpression of the polyoma middle T antigen oncoprotein under the MMTV promoter, and we observed tumor progression in heterozygous and homozygous mutant mice [59]. In the absence of CSF-1, tumorassociated macrophages were severely depleted. This had no effect on the incidence or growth of the primary tumor, but it reduced the rate of tumor progression to the more malignant states and almost completely suppressed metastasis to the lung [59]. Reintroduction of CSF-1 locally to the mammary epithelium by transgenic means recruited tumor-associated macrophages in control mice prematurely, and restored their density to the control levels seen in Csf1op/Csf1op mice [59]. This treatment accelerated tumor progression and the rate of metastasis in both genotypes.

Since macrophages are the only CSF-1R-bearing cells in the mouse tumors induced by polyoma middle $T$, these data provide strong evidence that macrophages provide help to tumor cells to grow and escape from their basement membranes such that they have access to the host vasculature. This process may also be enhanced by the angiogenic properties of macrophages at sites of leuko-

\section{Figure 4}

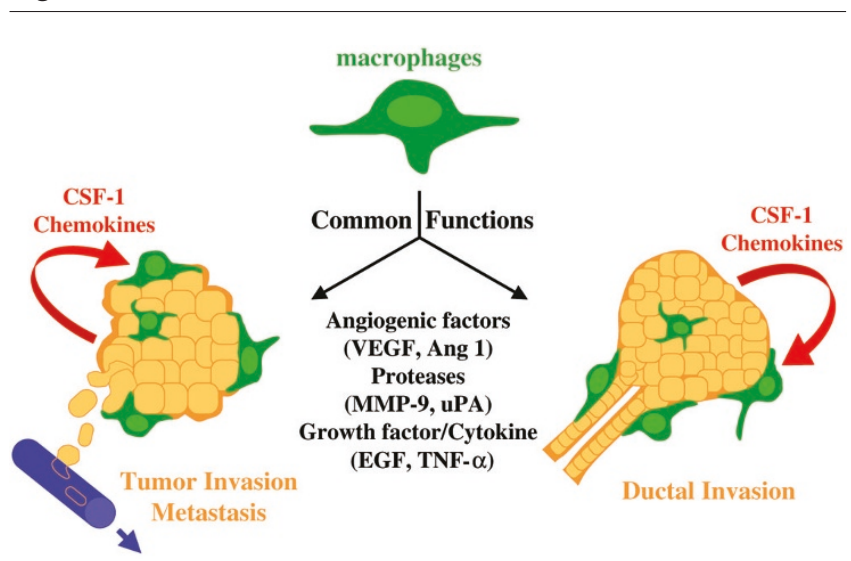

Model for macrophage potentiation of normal mammary gland development and for tumor progression. CSF-1/chemokines produced by the TEB or tumor regulate infiltration and activity of macrophages. These cells release growth factor remodeling signals and angiogenic factors that promote vascularization and/or invasion of mammary epithelial or tumor cells through the matrix. Ang, angiopoietin; EGF, epidermal growth factor; MMP, matrix metalloproteinase; TNF, tumor necrosis factor; uPA, urokinase plaminogen activator; VEGF, vascular endothelial growth factor.

cytic infiltration in the tumor $[47,60]$. It is notable that in human breast cancer there is a positive correlation between high vascular grade and increased macrophage index and a strong relationship between increased macrophage counts and reduced relapse-free survival and overall survival [58]. Our genetic experiments in mice indicate that these are causal relations and suggest possible therapeutic intervention aimed at inhibiting CSF-1R signaling.

\section{Eosinophils and eotaxin in mammary gland development}

Eotaxin is a powerful chemoattractant for eosinophils but not for mononuclear cells or neutrophils $[61,62]$. It acts to mobilize eosinophils and their progenitors from the bone marrow into the blood, and their subsequent recruitment into sites of allergic inflammation [63-66]. Besides its role in inflammation, eotaxin is also required for maintaining the physiological baseline trafficking of eosinophils in the jejunum during healthy states [67]. Eotaxin mRNA has been detected in the mammary gland [68], and our recent work showed that eosinophil recruitment to the prepubertal mammary gland coincided with a significant elevation in eotaxin mRNA transcript levels [7]. In mammary glands from eotaxin-deficient mice, the number of eosinophils around the TEBs dropped to $2 \%$ of the level found in wildtype mice [7], even though eosinophils have normal numbers in the bone marrow and peripheral blood of these mice $[65,69]$.

Among the known eosinophil chemotactic factors, IL-5 could also be considered as a candidate acting in the 
mammary gland. IL-5 is responsible for the proliferation, differentiation, recruitment and activation of eosinophils [70]. Although the eosinophil population is strongly depleted in the blood of IL-5-deficient mice, mammary ductal outgrowth is normal and eosinophils are still found around TEBs in these mice (V Gouon-Evans and JW Pollard, unpublished data). These observations agree with the notion that IL- 5 provides the signal for the release of a pool of eosinophils from the bone marrow, while eotaxin remains the critical local chemoattractant for eosinophils into the mammary gland.

Eosinophils are generally regarded as cells recruited to tissues as a host defense against parasites or during allergic responses $[71,72]$. They are also detected in a variety of healthy tissues, although their functions are not defined. For example, eosinophils reside in the jejunum and thymus of mice [67], and in the uterus they are recruited abundantly to the stroma at estrus under the influence of estrogen-regulated synthesis of eotaxin [73]. During postnatal mammary gland development, eosinophils occupy a unique position around the head of TEBs. In eotaxindeficient mice, the total ductal branch numbers were significantly reduced and TEB formation was affected, although to a lesser extent than in Csf1op/Csf1op mice [7]. However, in contrast to Csf1op/Csf1op mice, ductal elongation was not defective, indicating a more targeted role of eosinophils on the branching pattern. Moreover, eotaxin-deficient mice can lactate normally, suggesting a restricted role of eosinophils during pubertal mammary gland development.

The eotaxin receptor, CCR3, is predominantly expressed by the hematopoietic cells involved in an allergic response-eosinophils, basophils and $\mathrm{T}$ helper type 2 cells - but is never seen in neutrophils or macrophages [74-76]. Basophils are not found around the ducts in the pubertal mammary glands, nor are T cells (V Gouon-Evans and JW Pollard, unpublished data). Moreover, eotaxin has no chemoattractant effects on macrophages and neutrophils in models of inflammation in vivo [65] or in vitro [68]. As a result, it seems that eotaxin acts strictly as a chemoattractant for eosinophils homing around the mammary TEBs during their estrogen-induced growth. The analysis of mammary glands of eotaxin-deficient mice provided the first report of a beneficial role for eosinophils in a physiological process. Nevertheless, the molecular mechanism for eosinophil function in the mammary gland remains to be explained.

\section{Eosinophils and tumors}

Eosinophils are also found in many types of human cancers, including both hematological cancers, such as Hodgkin's lymphoma [77], as well as solid tumors [78-83]. Deposition of eosinophilic granular proteins has been found in of eosinophils was reported to be one indicator of increased survival in carcinoma of the uterine cervix [86], in breast cancer [87] and in gastric cancer [78]; however, it was also indicative of a less effective immune response in cervical cancer [81] or had no prognostic value in rectal cancer [79] or in nasopharyngeal carcinoma [82]. Thus, there is increasing evidence showing that eosinophils infiltrate into tumor sites, suggesting that these cells may play a role in host-tumor interactions.

\section{Macrophage/eosinophil interaction through the chemokine C10}

The colocalization of macrophages and eosinophils around TEBs suggests a possible interaction between these cells. In Csf1op/Csf1op mice, the first appearance of macrophages in the mammary gland was delayed and their number around TEBs was significantly reduced, to half that found in control mice [7]. This residual population suggests the presence of other locally derived factors recruiting macrophages besides CSF-1. Interestingly, the mouse chemokine $\mathrm{C} 10$, a chemoattractant for monocytes [88], was found exclusively in cytoplasmic granules of eosinophils around the TEBs (Fig. 5). Although C10 was originally identified in macrophages activated by granulocyte/macrophage-colony-stimulating factor [89], C10 has been recently found to be constitutively expressed in inflammatory eosinophils as well as in circulating eosinophils in healthy situations [90]. C10 is highly homologous to human chemokines such as MIP-1 [91], CCF18 [92], HCC-1, and HCC-2 [93]. These human chemokines possess similar affinity for $\mathrm{C}-\mathrm{C}$ chemokine receptor 1 and promote $\mathrm{T}$-cell and monocyte chemotaxis. This suggests that $\mathrm{C} 10$ secreted by eosinophils might constitute a chemokine acting to recruit macrophages around the growing TEBs. However, C10 is unlikely to be the dominant macrophage chemoattractant. Indeed, in the absence of CSF-1, macrophages are not seen around the ductal tree before TEB appearance, as opposed to observations in control mice, where macrophages are recruited around the rudimentary epithelial tree at 2.5 weeks of age [7]. Later on, however, when TEBs form, macrophages are found in association with C10-expressing eosinophils around TEBs even in CSF-1-deficient mice. These data indicate that CSF-1 is the first factor acting as a chemoattractant for macrophages in the mammary gland, while C10, whose expression depends on the eosinophil recruitment around TEBs, may constitute a late modulator of macrophage populations. Taken together, our data point out a possible interaction around the developing TEBs between macrophages and eosinophils through $\mathrm{C} 10$ production by eosinophils.

\section{Role of other cytokines/chemokines in mammary gland development}

Besides CSF-1, C10 and eotaxin, other chemokines/ cytokines that have been reported in the mammary gland 
Figure 5

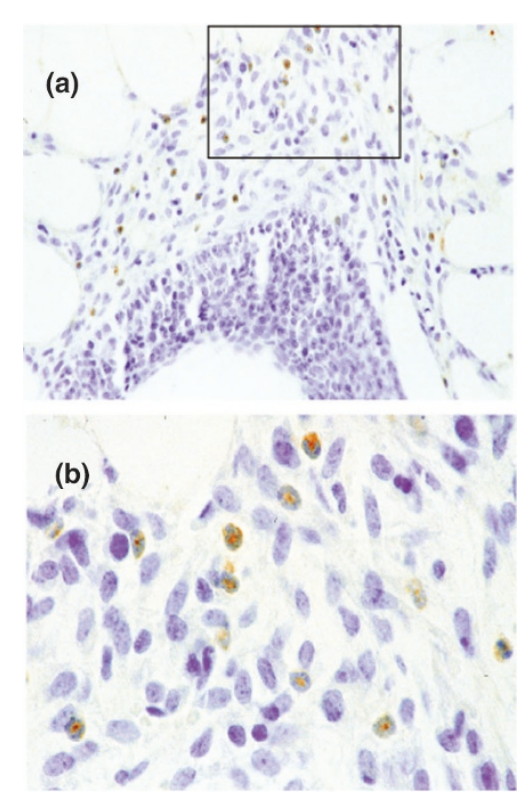

C10 expression in mammary gland. (a, b) $\mathrm{C} 10$ Immunohistochemistry of a longitudinal section of a TEB. $\mathrm{C} \mathrm{O}^{+}$cells are detected with a peroxidase-coupled detection system (brown coloration). (b) High magnification of the frame seen in (a). Note the positive eosinophils in the stroma surrounding epithelial cells of the TEB, characterized by their segmented nucleus, sometimes in a ring shape, with a round cytoplasmic shape. Original magnification: a, 400x; b 1000x.

tissue and milk could be involved in leukocyte homing and activation into the mammary gland at different stages of its development and differentiation [16,94].

Normal breast epithelial cells isolated from primary cultures of normal mammary epithelial cells or spontaneously immortalized mammary gland epithelial cells obtained from healthy women were shown to release IL-6 and IL-8 together with tumor-necrosis factor (TNF) [95,96]. As a result, IL-6 and IL-8 are detected in human milk. It is of interest that expression of IL-6 was abolished in ductal infiltrating carcinoma and greatly reduced in cultures of oncogene-transfected human mammary cells, suggesting that alterations of IL-6 expression are associated with pathogenesis in breast cancer [95,97].

Proteins of the TNF and TNF receptor family play important roles in the control of cell death, proliferation, autoimmunity, the function of immune cells and the organogenesis of lymphoid organs [98,99]. Recently, novel members of this large family have been identified that have critical functions in immunity and that couple lymphoid cells with other organ systems such as bone morphogenesis and mammary gland development in pregnancy. The TNF-family molecule RANK-L (receptor activator of nuclear factor $\kappa B$ ligand, also known as TRANCE,
TNF-related activation induced cytokine, or ODF, osteoclast differentiation factor) and its receptor RANK (receptor activator of nuclear factor $\kappa \mathrm{B}$ ), besides their critical functions in bone homeostasis, are expressed in mammary gland epithelial cells, and control the terminal differentiation of alveolar buds to create lobulo-alveolar structures competent for lactation [100]. Pregnant RANK-L-deficient mice fail to form lactating mammary tissues or produce the major milk protein, $\beta$-casein. Without RANK, the mammary epithelial cells undergo accelerated apoptosis because of a failure to activate the antiapoptotic protein kinase $B$ (PKB/AKT) [100]. TNF- $\alpha$, another member of the TNF family, has also been implicated in mammary morphogenesis. TNF- $\alpha$-deficient mice displayed fewer secondary and tertiary branches of the mammary epithelium during puberty; nevertheless, their lactational capability remained normal [101]. TNF- $\alpha$ was shown to stimulate growth as well as to induce extensive branching and alveolar morphogenesis of isolated rat mammary epithelial cells in primary culture, and, under optimal medium conditions, to inhibit the accumulation of casein proteins [102,103]. Interestingly, macrophages are a major producer of TNF- $\alpha$ [104], suggesting a role for macrophage-secreted TNF- $\alpha$ in the morphogenesis of mammary glands.

The mammary enriched chemokine (MEC) is a new member of the CC9 (beta) chemokine family and has been recently reported to be highly expressed in many human mammary gland epithelial tissues and to a lesser extent in other epithelial-enriched tissues, such as salivary gland, colon and prostate [105]. Interestingly, MEC expression is absent or reduced in various mammary tumor types, suggesting that MEC may play a regulatory role in regulating mammary carcinogenesis and may be a useful diagnostic tool in oncology.

A putative cytokine, HIN-1 (high in normal-1), has been newly identified and shown to be highly expressed in normal human luminal mammary epithelial cells but hypermethylated and not expressed in the majority of breast cancers [106].

\section{Conclusion}

It is clear that the stroma of the developing mammary gland and mammary tumor is constantly changing, not only through movement and differentiation of resident cells, but also by recruitment of migrating hematopoietic cells, particularly macrophages and eosinophils. The activity of these latter cells brings a new factor for consideration in the regulation of mammary ductal elongation/differentiation and tumorigenesis. Indeed, the spatial and temporal secretion of cytokines/chemokines, including CSF-1, eotaxin and C10, controls the homing of macrophages and eosinophils into the stroma adjacent to the mammary epithelium, which in turn influence ductal epithelium morphogenesis. During postnatal development, pregnancy 
and lactation in mice, macrophages, being the only CSF-1R-bearing cells, are the key players of the CSF-1/ CSF-1R system acting on ductal outgrowth/differentiation; whereas in humans, in combination with macrophages, the CSF-1R-expressing epithelium also participates in mammary differentiation during pregnancy and lactation. Eosinophils have a function restricted to postnatal mammary development, where they may interact with macrophages to induce proper branching morphogenesis. Because of the similarities between macrophages adjacent to a growing TEB and in invading mammary tumors, it seems that tumors have co-opted normal developmental signals to facilitate their growth and progression. Understanding the similarities and differences between these processes may reveal a target that can be exploited as part of therapeutic armory against breast cancer.

\section{Ackowledgements}

We thank Liyin Zhu for help with the immunohistochemistry of pregnant and lactating mammary glands and Dr Amos Orlofsky (Department of Pathology, Albert Einstein College of Medicine) for the anti-C10 antibody. This work was supported by grants from the National Institutes of Health RO1HD 30280 (JWP) and DOD\#17-97-1-7153 postdoctoral fellowship to Dr Valérie Gouon-Evans, and by the Einstein Cancer Center grant P30-13330.

\section{References}

1. Robinson GW, Karpf AB, Kratochwil K: Regulation of mammary gland development by tissue interaction. J Mammary Gland Biol Neoplasia 1999, 4:9-19.

2. Sakakura T, Sakagami Y, Nishizuka Y: Dual origin of mesenchymal tissues participating in mouse mammary gland embryogenesis. Dev Biol 1982, 91:202-207.

3. Enami J, Enami S, Koga M: Growth of normal and neoplastic mouse mammary epithelial cells in primary culture: stimulation by conditioned medium from mouse mammary fibroblasts. Gann 1983, 74:845-853.

4. Levine JF, Stockdale FE: 3T3-L1 adipocytes promote the growth of mammary epithelium. Exp Cell Res 1984, 151:112-122.

5. Carrington CA, Hosick HL: Effects of dietary fat on the growth of normal, preneoplastic and neoplastic mammary epithelial cells in vivo and in vitro. J Cell Sci 1985, 75:269-278.

6. Berdichevsky F, Alford D, D'Souza B, Taylor-Papadimitriou J: Branching morphogenesis of human mammary epithelial cells in collagen gels. J Cell Sci 1994, 107:3557-3568.

7. Gouon-Evans V, Rothenberg ME, Pollard JW: Postnatal mammary gland development requires macrophages and eosinophils. Development 2000, 127:2269-2282.

8. Silberstein GB: Tumour-stromal interactions. Role of the stroma in mammary development. Breast Cancer Res 2001, 3: 218-223.

9. McKnight AJ, Macfarlane AJ, Dri P, Turley L, Willis AC, Gordon S: Molecular cloning of F4/80, a murine macrophage-restricted cell surface glycoprotein with homology to the G-proteinlinked transmembrane 7 hormone receptor family. J Biol Chem 1996, 271:486-489.

10. Szewczyk G, Szukiewicz D, Zaczek R, Maslinska D: Mast cells in the mouse mammary gland-correlation with the development of lactiferous structures. Folia Biol 2000, 48:13-17.

11. Outteridge PM, Lee CS: Cellular immunity in the mammary gland with particular reference to $T, B$ lymphocytes and macrophages. Adv Exp Med Biol 1981, 137:513-534.

12. Lee CS, Outteridge PM: Leucocytes of sheep colostrum, milk and involution secretion, with particular reference to ultrastructure and lymphocyte sub-populations. J Dairy Res 1981, 48:225-237.

13. Hara T, Irie K, Saito S, Ichijo M, Yamada M, Yanai N, Miyazaki S: Identification of macrophage colony-stimulating factor in human milk and mammary gland epithelial cells. Pediatr Res 1995, 37:437-443.
14. Riollet $C$, Rainard $P$, Poutrel $B$ : Cells and cytokines in inflammatory secretions of bovine mammary gland. Adv Exp Med Biol 2000, 480:247-258.

15. Roux ME, McWilliams M, Phillips-Quagliata JM, Weisz-Carrington $\mathrm{P}$, Lamm ME: Origin of IgA-secreting plasma cells in the mammary gland. J Exp Med 1977, 146:1311-1322.

16. Goldman AS, Chheda S, Garofalo R, Schmalstieg FC: Cytokines in human milk: properties and potential effects upon the mammary gland and the neonate. J Mammary Gland Biol Neoplasia 1996, 1:251-258.

17. Wagstrom EA, Yoon KJ, Zimmerman JJ: Immune components in porcine mammary secretions. Viral Immunol 2000, 13:383-397.

18. Hanson LA: The mother-offspring dyad and the immune system. Acta Paediatr 2000, 89:252-258.

19. van der Feltz MJ, de Groot N, Bayley JP, Lee SH, Verbeet MP, de Boer HA: Lymphocyte homing and Ig secretion in the murine mammary gland. Scand J Immunol 2001, 54:292-300.

20. Lee CS, McCauley I, Hartmann PE: Light and electron microscopy of cells in pig colostrum, milk and involution secretion. Acta Anat 1983, 116:126-135.

21. Colditz IG: Studies on the inflammatory response during involution of the ovine mammary gland. $Q J$ Exp Physiol 1988, 73: 363-368

22. Tatarczuch L, Philip C, Bischof R, Lee CS: Leucocyte phenotypes in involuting and fully involuted mammary glandular tissues and secretions of sheep. J Anat 2000, 196:313-326.

23. Sordillo LM, Shafer-Weaver K, DeRosa D: Immunobiology of the mammary gland. J Dairy Sci 1997, 80:1851-1865.

24. Paape MJ, Shafer-Weaver K, Capuco AV, Van Oostveldt K, Burvenich $\mathrm{C}$ : Immune surveillance of mammary tissue by phagocytic cells. Adv Exp Med Biol 2000, 480:259-277.

25. Stanley ER, Guilbert LJ, Tushinski RJ, Bartelmez SH: CSF-1 a mononuclear phagocyte lineage-specific hemopoietic growth factor. J Cell Biochem 1983, 21:151-159.

26. Tushinski RJ, Stanley ER: The regulation of macrophage protein turnover by a colony stimulating factor (CSF-1). J Cell Physiol 1983, 116:67-75.

27. Roth $\mathrm{P}$, Stanley ER: The biology of CSF-1 and its receptor. Curr Top Microbiol Immunol 1992, 181:141-167.

28. Tushinski RJ, Oliver IT, Guilbert LJ, Tynan PW, Warner JR, Stanley ER: Survival of mononuclear phagocytes depends on a lineage-specific growth factor that the differentiated cells selectively destroy. Cell 1982, 28:71-81.

29. Pollard JW: Role of colony-stimulating factor-1 in reproduction and development. Mol Reprod Dev 1997, 46:54-60; discussion 60-51.

30. Sherr CJ, Rettenmier CW, Sacca R, Roussel MF, Look AT, Stanley ER: The c-fms proto-oncogene product is related to the receptor for the mononuclear phagocyte growth factor, CSF-1. Cell 1985, 41:665-676.

31. Li W, Stanley ER: Role of dimerization and modification of the CSF-1 receptor in its activation and internalization during the CSF-1 response. EMBO J 1991, 10:277-288.

32. Rohrschneider LR, Bourette RP, Lioubin MN, Algate PA, Myles GM, Carlberg K: Growth and differentiation signals regulated by the M-CSF receptor. Mol Reprod Dev 1997, 46:96-103.

33. Pixley FJ, Lee PS, Condeelis JS, Stanley ER: Protein tyrosine phosphatase phi regulates paxillin tyrosine phosphorylation and mediates colony-stimulating factor 1-induced morphological changes in macrophages. Mol Cell Biol 2001, 21:17951809.

34. Wiktor-Jedrzejczak W, Bartocci A, Ferrante AW, Jr., AhmedAnsari A, Sell KW, Pollard JW, Stanley ER: Total absence of colony-stimulating factor 1 in the macrophage-deficient osteopetrotic (op/op) mouse. Proc Natl Acad Sci USA 1990, 87:4828-4832.

35. Yoshida H, Hayashi S, Kunisada T, Ogawa M, Nishikawa S, Okamura H, Sudo T, Shultz LD: The murine mutation osteopetrosis is in the coding region of the macrophage colony stimulating factor gene. Nature 1990, 345:442-444.

36. Pollard JW, Stanley ER: Pleiotropic roles for CSF-1 in development defined by the mouse mutation osteopetrotic (op). Advances in Developmental Biochemistry 1996, 4:153-193.

37. Dai XM, Ryan GR, Hapel AJ, Dominguez MG, Russell RG, Kapp $\mathrm{S}$, Sylvestre V, Stanley ER: Targeted disruption of the mouse colony-stimulating factor 1 receptor gene results in osteopetrosis, mononuclear phagocyte deficiency, increased primitive 
progenitor cell frequencies, and reproductive defects. Blood 2002, 99:111-120.

38. Pollard JW, Hennighausen L: Colony stimulating factor 1 is required for mammary gland development during pregnancy. Proc Natl Acad Sci USA 1994, 91:9312-9316.

39. Cohen PE, Zhu L, Nishimura K, Pollard JW: Colony-stimulating factor 1 regulation of neuroendocrine pathways that control gonadal function in mice. Endocrinology 2002, 143:1413-1422.

40. Nguyen AV, Pollard JW: Colony stimulating factor- 1 is required to recruit macrophages into the mammary gland to facilitate mammary ductal outgrowth. Dev Bio/ 2002, 247:11-25.

41. Ryan GR, Dai XM, Dominguez MG, Tong W, Chuan F, Chisholm O, Russell RG, Pollard JW, Stanley ER: Rescue of the colonystimulating factor 1 (CSF-1)-nullizygous mouse (Csf1op/ Csf1 ${ }^{\circ}$ ) phenotype with a CSF-1 transgene and identification of sites of local CSF-1 synthesis. Blood 2001, 98:74-84.

42. Kacinski BM: CSF-1 and its receptor in breast carcinomas and neoplasms of the female reproductive tract. Mol Reprod Dev 1997, 46:71-74.

43. Sapi E, Flick MB, Rodov S, Carter D, Kacinski BM: Expression of CSF-I and CSF-I receptor by normal lactating mammary epithelial cells. J Soc Gynecol Invest 1998, 5:94-101.

44. Kacinski BM, Scata KA, Carter D, Yee LD, Sapi E, King BL, Chambers SK, Jones MA, Pirro MH, Stanley ER, Rohrschneider LR: FMS (CSF-1 receptor) and CSF-1 transcripts and protein are expressed by human breast carcinomas in vivo and in vitro. Oncogene 1991, 6:941-952.

45. Welgus HG, Senior RM, Parks WC, Kahn AJ, Ley TJ, Shapiro SD, Campbell EJ: Neutral proteinase expression by human mononuclear phagocytes: a prominent role of cellular differentiation. Matrix Supp/ 1992, 1:363-367.

46. Horton MA (Ed): Blood Cell Biochemistry, Macrophages and Related Cells. Vol 5. Edn 5. New York: Plenum Press; 1996.

47. Polverini PJ: Role of the macrophage in angiogenesis-dependent diseases. EXS 1997, 79:11-28.

48. Hogg NA, Harrison CJ, Tickle C: Lumen formation in the developing mouse mammary gland. J Embryol Exp Morphol 1983, 73:39-57.

49. Humphreys RC, Krajewska M, Krnacik S, Jaeger R, Weiher H, Krajewski S, Reed JC, Rosen JM: Apoptosis in the terminal endbud of the murine mammary gland: a mechanism of ductal morphogenesis. Development 1996, 122:4013-4022.

50. Sapi E, Kacinski BM: The role of CSF-1 in normal and neoplastic breast physiology. Proc Soc Exp Biol Med 1999, 220:1-8

51. Lin EY, Gouon-Evans V, Nguyen AV, Pollard JW: The macrophage growth factor, CSF-1, in mammary gland development and tumor progression. J Mammary Gland Biol Neoplasia 2002:in press.

52. O'Sullivan C, Lewis CE: Tumour-associated leucocytes: friends or foes in breast carcinoma. J Pathol 1994, 172:229-235.

53. Elgert KD, Alleva DG, Mullins DW: Tumor-induced immune dysfunction: the macrophage connection. J Leukoc Biol 1998, 64: 275-290

54. Bingle L, Brown NJ, Lewis CE: The role of tumour-associated macrophages in tumour progression: implications for new anticancer therapies. J Patho/ 2002, 196:254-265.

55. Mantovani A, Bottazzi B, Colotta F, Sozzani S, Ruco L: The origin and function of tumor-associated macrophages. Immunol Today 1992, 13:265-270.

56. Scholl SM, Pallud C, Beuvon F, Hacene K, Stanley ER, Rohrschneider L, Tang R, Pouillart P, Lidereau R: Anti-colonystimulating factor-1 antibody staining in primary breast adenocarcinomas correlates with marked inflammatory cell infiltrates and prognosis. J Natl Cancer Inst 1994, 86:120-126.

57. Leek RD, Lewis CE, Whitehouse R, Greenall M, Clarke J, Harris $\mathrm{AL}$ : Association of macrophage infiltration with angiogenesis and prognosis in invasive breast carcinoma. Cancer Res 1996, 56:4625-4629

58. Leek RD, Harris AL: Tumour associated macrophages in breast cancer. J Mammary Gland Biol Neoplasia 2002:in press.

59. Lin EY, Nguyen AV, Russell RG, Pollard JW: Colony-stimulating factor 1 promotes progression of mammary tumors to malignancy. J Exp Med 2001, 193:727-740.

60. Crowther M, Brown NJ, Bishop ET, Lewis CE: Microenvironmental influence on macrophage regulation of angiogenesis in wounds and malignant tumors. J Leukoc Biol 2001, 70:478490 .
61. Garcia-Zepeda EA, Rothenberg ME, Ownbey RT, Celestin J, Leder $\mathrm{P}$, Luster AD: Human eotaxin is a specific chemoattractant for eosinophil cells and provides a new mechanism to explain tissue eosinophilia. Nat Med 1996, 2:449-456.

62. Sabroe I, Hartnell A, Jopling LA, Bel S, Ponath PD, Pease JE, Collins PD, Williams TJ: Differential regulation of eosinophil chemokine signaling via CCR3 and non-CCR3 pathways. J Immunol 1999, 162:2946-2955.

63. Ganzalo JA, Jia GQ, Aguirre V, Friend D, Coyle AJ, Jenkins NA, Lin GS, Katz H, Lichtman A, Copeland N,, Kopf M, Gutierrez-Ramos JC: Mouse eotaxin expression parallels eosinophil accumulation during lung allergic inflammation but it is not restricted to a Th2-type response. Immunity 1996, 4:1-14.

64. Baggiolini M, Dewald B, Moser B: Human chemokines: an update. Annu Rev Immunol 1997, 15:675-705.

65. Rothenberg ME, MacLean JA, Pearlman E, Luster AD, Leder P: Targeted disruption of the chemokine eotaxin partially reduces antigen-induced tissue eosinophilia. J Exp Med 1997, 185:785-790.

66. Palframan RT, Collins PD, Williams TJ, Rankin SM: Eotaxin induces a rapid release of eosinophils and their progenitors from the bone marrow. Blood 1998, 91:2240-2248.

67. Matthews AN, Friend DS, Zimmermann N, Sarafi MN, Luster AD, Pearlman E, Wert SE, Rothenberg ME: Eotaxin is required for the baseline level of tissue eosinophils. Proc Natl Acad Sci USA 1998, 95:6273-6278.

68. Rothenberg ME, Luster AD, Leder $P$ : Murine eotaxin: an eosinophil chemoattractant inducible in endothelial cells and in interleukin 4-induced tumor suppression. Proc Natl Acad Sci USA 1995, 92:8960-8964.

69. Mishra A, Hogan SP, Lee JJ, Foster PS, Rothenberg ME: Fundamental signals that regulate eosinophil homing to the gastrointestinal tract. J Clin Invest 1999, 103:1719-1727.

70. Sanderson CJ: Interleukin-5, eosinophils, and disease. Blood 1992, 79:3101-3109.

71. Gleich GJ, Adolphson CR: The eosinophilic leukocyte: structure and function. Adv Immunol 1986, 39:177-253.

72. Rothenberg ME: Eosinophilia. N Engl J Med 1998, 338:1592 1600.

73. Gouon-Evans V, Pollard JW: Eotaxin is required for eosinophil homing into the stroma of the pubertal and cycling uterus. Endocrinology 2001, 142:4515-4521.

74. Uguccioni M, Mackay CR, Ochensberger B, Loetscher P, Rhis S, LaRosa GJ, Rao P, Ponath PD, Baggiolini M, Dahinden CA: High expression of the chemokine receptor CCR3 in human blood basophils. Role in activation by eotaxin, MCP-4, and other chemokines. J Clin Invest 1997, 100:1137-1143.

75. Yamada H, Hirai K, Miyamasu M, likura M, Misaki Y, Shoji S, Takaishi T, Kasahara T, Morita Y, Ito K: Eotaxin is a potent chemotaxin for human basophils. Biochem Biophys Res Commun 1997, 231:365-368.

76. Sallusto F, Mackay CR, Lanzavecchia A: Selective expression of the eotaxin receptor CCR3 by human T helper 2 cells. Science 1997, 277:2005-2007.

77. Samoszuk M, Ramzi E: IgE, Reed-Sternberg cells, and eosinophilia in Hodgkin's disease. Leuk Lymphoma 1993, 9: 315-319.

78. Iwasaki $\mathrm{K}$, Torisu M, Fujimura $\mathrm{T}$ : Malignant tumor and eosinophils. I. Prognostic significance in gastric cancer. Cancer 1986, 58:1321-1327.

79. Fisher ER, Paik SM, Rockette H, Jones J, Caplan R, Fisher B: Prognostic significance of eosinophils and mast cells in rectal cancer: findings from the National Surgical Adjuvant Breast and Bowel Project (protocol R-01). Hum Pathol 1989, 20:159-163.

80. Goldsmith MM, Belchis DA, Cresson DH, Merritt WD 3rd, Askin FB: The importance of the eosinophil in head and neck cancer. Otolaryngol Head Neck Surg 1992, 106:27-33.

81. van Driel WJ, Hogendoorn PC, Jansen FW, Zwinderman $A H$, Trimbos JB, Fleuren GJ: Tumor-associated eosinophilic infiltrate of cervical cancer is indicative for a less effective immune response. Hum Pathol 1996, 27:904-911.

82. Leighton SE, Teo JG, Leung SF, Cheung AY, Lee JC, van Hasselt $\mathrm{CA}$ : Prevalence and prognostic significance of tumor-associated tissue eosinophilia in nasopharyngeal carcinoma. Cancer 1996, 77:436-440.

83. Samoszuk M: Eosinophils and human cancer. Histol Histopathol 1997, 12:807-812. 
84. Samoszuk MK, Nguyen V, Gluzman I, Pham JH: Occult deposition of eosinophil peroxidase in a subset of human breast carcinomas. Am J Pathol 1996, 148:701-706.

85. Samoszuk M, Lin F, Rim P, Strathearn G: New marker for blood vessels in human ovarian and endometrial cancers. Clin Cancer Res 1996, 2:1867-1871.

86. Bethwaite PB, Holloway LJ, Yeong ML, Thornton A: Effect of tumour associated tissue eosinophilia on survival of women with stage IB carcinoma of the uterine cervix. J Clin Pathol 1993, 46:1016-1020.

87. Ownby HE, Roi LD, Isenberg RR, Brennan MJ: Peripheral lymphocyte and eosinophil counts as indicators of prognosis in primary breast cancer. Cancer 1983, 52:126-130.

88. Berger MS, Taub DD, Orlofsky A, Kleyman TR, Coupaye-Gerard $B$, Eisner D, Cohen SA: The chemokine C10: immunological and functional analysis of the sequence encoded by the novel second exon. Cytokine 1996, 8:439-447.

89. Orlofsky A, Berger MS, Prystowsky MB: Novel expression pattern of a new member of the MIP-1 family of cytokine-like genes. Cell Regul 1991, 2:403-412.

90. Wu Y, Prystowsky MB, Orlofsky A: Sustained high-level production of murine chemokine $\mathrm{C} 10$ during chronic inflammation. Cytokine 1999, 11:523-530.

91. Wang W, Bacon KB, Oldham ER, Schall TJ: Molecular cloning and functional characterization of human MIP-1 delta, a new C-C chemokine related to mouse CCF-18 and C10. J Clin Immunol 1998, 18:214-222.

92. Hara T, Bacon KB, Cho LC, Yoshimura A, Morikawa Y, Copeland NG, Gilbert DJ, Jenkins NA, Schall TJ, Miyajima A: Molecular cloning and functional characterization of a novel member of the C-C chemokine family. J Immunol 1995, 155:5352-5358.

93. Pardigol A, Forssmann U, Zucht HD, Loetscher P, SchulzKnappe P, Baggiolini M, Forssmann WG, Magert HJ: HCC-2, a human chemokine: gene structure, expression pattern, and biological activity. Proc Natl Acad Sci USA 1998, 95:63086313.

94. Garofalo RP, Goldman AS: Cytokines, chemokines, and colony-stimulating factors in human milk: the 1997 update. Biol Neonate 1998, 74:134-142.

95. Basolo F, Conaldi PG, Fiore L, Calvo S, Toniolo A: Normal breast epithelial cells produce interleukins 6 and 8 together with tumor-necrosis factor: defective IL6 expression in mammary carcinoma. Int J Cancer 1993, 55:926-930.

96. Palkowetz KH, Royer CL, Garofalo R, Rudloff HE, Schmalstieg FC, Jr., Goldman AS: Production of interleukin-6 and interleukin- 8 by human mammary gland epithelial cells. $J$ Reprod Immunol 1994, 26:57-64.

97. Basolo F, Fiore L, Calvo S, Falcone V, Conaldi PG, Fontanini G, Caligo AM, Merlo G, Gluzman Y, Toniolo A: Defective interleukin six expression and responsiveness in human mammary cells transformed by an adeno 5/SV40 hybrid virus. $B r$ J Cancer 1996, 73:1356-1361.

98. Locksley RM, Killeen N, Lenardo MJ: The TNF and TNF receptor superfamilies: integrating mammalian biology. Cell 2001, 104:487-501.

99. Theill LE, Boyle WJ, Penninger JM: RANK-L AND RANK: T cells, bone loss, and mammalian evolution. Annu Rev Immunol 2002, 20:795-823.

100. Fata JE, Kong YY, Li J, Sasaki T, Irie-Sasaki J, Moorehead RA, Elliott R, Scully S, Voura EB, Lacey DL, Voura EB, Lacey DL, Boyle WJ, Khokha R, Penninger JM: The osteoclast differentiation factor osteoprotegerin-ligand is essential for mammary gland development. Cell 2000, 103:41-50

101. Stangle NC, Kollias G, Ip MM: Disrupted mammary gland development in TNF $\alpha$ knockout mice [abstract]. Proc $\mathrm{Am}$ Assoc Cancer Res 1999, 40:161.

102. Ip MM, Shoemaker SF, Darcy KM: Regulation of rat mammary epithelial cell proliferation and differentiation by tumor necrosis factor-alpha. Endocrinology 1992, 130:2833-2844.

103. Varela LM, Ip MM: Tumor necrosis factor-alpha: a multifunctional regulator of mammary gland development. Endocrino/ogy 1996, 137:4915-4924.

104. Nathan CF: Secretory products of macrophages. J Clin Invest 1987, 79:319-326.

105. Mickanin CS, Bhatia U, Labow M: Identification of a novel betachemokine, MEC, down-regulated in primary breast tumors. Int J Oncol 2001, 18:939-944.
106. Krop IE, Sgroi D, Porter DA, Lunetta KL, LeVangie R, Seth $P$, Kaelin CM, Rhei E, Bosenberg M, Schnitt S, Marks JR, Pagon Z, Belina D, Razumovic J, Polyak K: HIN-1, a putative cytokine highly expressed in normal but not cancerous mammary epithelial cells. Proc Natl Acad Sci USA 2001, 98:9796-9801. 